\title{
Addenbrooke's cognitive examination III in the diagnosis of dementia: a critical review
}

This article was published in the following Dove Medical Press journal:

Neuropsychiatric Disease and Treatment

\author{
Diana Bruno ${ }^{1,2}$ \\ Sofia Schurmann Vignaga ${ }^{2}$ \\ 'Instituto de Investigación en \\ Psicología Básica y Aplicada (IIPBA), \\ Facultad de Filosofía y Humanidades, \\ Universidad Católica de Cuyo, \\ J5400 Rivadavia, San Juan, Argentina; \\ ${ }^{2}$ Neuropsicología y Rehabilitación \\ Cognitiva, Instituto de Neurociencias \\ Cognitivas y Traslacional (INCyT), \\ Fundación INECO, Universidad \\ Favaloro, CONICET, Buenos Aires, \\ Argentina
}

\begin{abstract}
Addenbrooke's cognitive examination III is a screening test that is composed of tests of attention, orientation, memory, language, visual perceptual and visuospatial skills. It is useful in the detection of cognitive impairment, especially in the detection of Alzheimer's disease and fronto-temporal dementia. The aim of this study is to do a critical review of the Addenbrooke's cognitive examination III. The different language versions available and research about the different variables that have relationship with the performance of the subject in the ACE-III are listed. The ACE-III is a detection technique that can differentiate patients with and without cognitive impairment, is sensitive to the early stages of dementia, and is available in different languages. However, further research is needed to obtain optimal cutoffs for the different versions and to evaluate the impact of different age, gender, IQ, and education variables on the performance of the test.
\end{abstract}

Keywords: dementia, cognitive assessment, memory, screening, cognitive impairment

\section{Introduction}

The Addenbrooke's cognitive examination (ACE) was developed by Hodges et al as an extended cognitive screening technique, designed to detect dementia and differentiate Alzheimer dementia from fronto-temporal dementia. ${ }^{1}$ It was also developed to overcome the neuropsychological omissions present in the Mini Mental State Examination (MMSE). ${ }^{2}$ The aim of ACE was to be a screening technique that evaluates the principal cognitive functions and grants free access to health professionals. ${ }^{3}$ In this way, ACE turns into a brief cognitive screening tool, which takes 15-20 minutes to administer and is useful in the detection of dementia syndromes. ${ }^{4}$

The ACE is composed of tests of attention, orientation, memory, language, visual perception and visuospatial skills. ${ }^{3}$ All of these measures have significant correlations with the classical neuropsychological tests. ${ }^{4}$

The aim of this study is to critically review the Addenbrooke's cognitive examination III.

\section{Description of ACE-III}

The ACE-III was developed to remove the MMSE elements from the ACE and ACE-R, as the MMSE was no longer open access in the year 2001. ${ }^{5}$ Because of this, recent guidelines have provided alternatives to the MMSE, and the ACE-III has been recommended by the Department of Health and the Alzheimer's Society in the UK. ${ }^{6}$ In this way, the MMSE items present in the ACE-R were substituted for by similar items. ${ }^{1}$ For example, in the attention section the spelling of the word "WORLD" backwards was omitted, leaving only the subtraction of serial 7s. In the language section,
Correspondence: Diana Bruno

Instituto de Investigación en Psicología Básica y Aplicada (IIPBA), Facultad de Filosofía y Humanidades, Universidad Católica de Cuyo, Av. José Ignacio de la Roza 1516 Oeste - Rivadavia C.P., 5400 San Juan, Argentina Tel +54264 4292300

Email dbruno@ineco.org.ar 
the written command "close your eyes" was omitted, the denomination of a pencil and clock was replaced by a book and a spoon, and the three-step command was replaced by three single-step commands, due to the lack of sensitivity to cognitive impairment. ${ }^{1,4}$ Finally, in the same section, the writing of a single sentence was replaced by writing two or more sentences. In the visuospatial section, the intersecting pentagons were replaced with intersecting lemnisci. ${ }^{3}$ Hence, with these changes the administration of the ACE-III makes scoring the MMSE void. ${ }^{4}$ As the ACE-III is designed to address the weakness of the ACE-R, the verbal repetition item was modified due to the poor performance of this item in healthy adults. ${ }^{3}$

As previously described, the ACE-III is composed of five cognitive domains, attention, memory, language, verbal fluency, and visuospatial abilities. The ACE-III takes $\sim 20$ minutes to complete (Table 1). Similarly to the ACE-R, the total score of the ACE-III is based on a maximum score of 100 , with higher scores indicating better cognitive functioning.

The index study of the ACE-III demonstrated high sensitivity and specificity, with cutoffs recommended as for the ACE-R as follows: 1) 88 (sensitivity $=1.0$; specificity $=0.96$ ) and 2$) 82$ (sensitivity $=0.93$; specificity $=1.0){ }^{4}$

\section{Correlation of ACE-III with neuropsychological tests}

It has been demonstrated that the subtests of the ACE-III have significant correlations with neuropsychological tests in that domain. The memory domain of the ACE correlated with two classical neuropsychological tests of memory, Free and Cued Selective Reminding Test and the Rey Auditory
Verbal Learning Test. ${ }^{4,7}$ The language domain correlated with the Boston Naming Test, the attention domain correlated with tests that evaluate attention and executive functions (the trail making test, memory span, Stroop test), and the fluency scores correlated with executive functions. ${ }^{7}$ Therefore, the administration of this screening technique quickly provides the clinician with a neuropsychological profile.

The cutoff points of ACE-III show strong correlations with the cutoff points of the ACE-R, ${ }^{4}$ suggesting that this screening technique is capable of differentiating patients with and without cognitive impairment, and mild cognitive impairment (MCI). ${ }^{3}$ In addition, the ACE-III performance has broader clinical implications in that it relates to carer reports of functional impairment in most common dementias. ${ }^{8}$

\section{Comparison of the ACE-III with other screening techniques}

In different studies that compare the ability to discriminate healthy people and people with dementia, the ACE-III showed similar results to other screening techniques ${ }^{9}$ $\left(\mathrm{MoCA}^{10}\right.$ and RUDAS $\left.{ }^{11}\right)$.

Like the other screening techniques (MMSE, MOCA, RUDAS), the ACE-III provides the clinician with a quick and brief global cognitive screen of the patient specifying both the overall cognitive profile and measures of each of the evaluated domains. ${ }^{9,10}$ In this way, ACE-III provides the clinician with a more comprehensive assessment view of the cognitive profile of the patient, helping to provide a differential diagnosis. ${ }^{12}$ Moreover, as the ACE-III includes different scores for each domain, in addition of the general

Table I Cognitive domain, tasks, and sub-total score of ACE-III

\begin{tabular}{|c|c|c|}
\hline $\begin{array}{l}\text { Cognitive } \\
\text { domains }\end{array}$ & Tasks & $\begin{array}{l}\text { Sub-total } \\
\text { score }\end{array}$ \\
\hline Attention & $\begin{array}{l}\text { Attention is tested by asking the patient about the date, including the season and the current location; repeating } \\
\text { back three simple words; and serial subtraction }\end{array}$ & 18 points \\
\hline Memory & $\begin{array}{l}\text { Memory is tested by asking the patient to recall three words previously repeated; memorizing and recalling a } \\
\text { fictional name and address; and recalling widely known historical facts }\end{array}$ & 26 points \\
\hline Fluency & $\begin{array}{l}\text { Fluency is tested by asking the patient to say as many words as they can think of starting with a specified letter } \\
\text { within I minute; and naming as many animals as they can think of in I minute }\end{array}$ & 14 points \\
\hline Language & $\begin{array}{l}\text { Language is tested by asking the patient to complete a set of sequenced physical commands using a pencil and } \\
\text { piece of paper such as "place the paper on top of the pencil," to write two grammatically complete sentences, } \\
\text { to repeat several polysyllabic words and two short proverbs; to name the objects shown in } 12 \text { line drawings, } \\
\text { and to answer contextual questions about some of the objects; and to read words with irregular sound-spelling } \\
\text { correspondence }\end{array}$ & 26 points \\
\hline Visuospatial & $\begin{array}{l}\text { Visuospatial abilities are tested by asking the patient to copy two diagrams, to draw a clock face with the hands } \\
\text { set at a specified time, to count sets of dots, and to recognize four fragmented letters }\end{array}$ & 16 points \\
\hline
\end{tabular}

Abbreviation: ACE-III, Addenbrooke's cognitive examination III. 
score, it allows for tracking the progression of cognitive deficits over time. ${ }^{13}$

The MMSE lacks sensitivity to identify fronto-temporal dementias, whereas the ACE-III had demonstrated accuracy for detecting fronto-temporal dementia. ${ }^{4}$ An important limitation of the MMSE is the lack of sensitivity for the early stages of dementia, ${ }^{14}$ whereas the ACE-III had demonstrated accuracy in detecting MCI. The ACE-III showed better sensitivity for detecting dementia compared to the MMSE. ${ }^{15}$ The ACE-III more efficiently identifies everyday functional impairments compared with both the MMSE and MoCA. ${ }^{16}$

Despite the above considerations, the MMSE continues to be the preferred screening instrument for many neurologists. For this reason, a conversion table between ACE-III and MMSE has been developed and is used for clinical and research purposes. ${ }^{17}$

In addition, a study by Larner investigated the relationship between administration time and diagnostic accuracy in cognitive screening tests. The author reports positive correlations between the accuracy and time of administration of the test and significant correlations between the accuracy and the number of items included in the test. These observations suggest that tests with more items (ie, longer tests) are more accurate. ${ }^{18}$ The number of items of the MMSE is 30 compared with the ACE-III, which have 100 items.

\section{Utility of the ACE-III in the detection of cognitive impairment}

Dementia has been declared a global challenge, causes a great burden for the families of the patients, and leads to enormous global annual costs, which are expected to increase significantly in the next few decades. ${ }^{20-22}$ Although several risk factors are implicated, the principal risk factor is age, and wit aging and growing populations dementia is becoming more prevalent. ${ }^{22}$ Therefore, it is essential that a sensitive and specific screening tool that not only identifies patients with dementia but also identifies them in the early stages of the disease will be widely used to allow earlier diagnosis and intervention and to postpone dementia. ${ }^{23}$

\section{$\mathrm{MCl}$}

MCI is the prodromal phase associated with brain disorders, including of Alzheimer's disease, ${ }^{24}$ Parkinson's disease, ${ }^{25}$ cerebrovascular disease, ${ }^{26}$ and fronto-temporal dementia. ${ }^{27}$

The ACE-III has shown high diagnostic accuracy for $\mathrm{MCI}$, being the memory domain the most sensitive in early stages of Alzheimer's disease patients. ${ }^{7}$ Moreover, the
ACE-III has demonstrated high diagnostic accuracy in individuals with subjective cognitive impairment. ${ }^{28}$

\section{Dementia}

The ACE-III, like its predecessors, was designed for the detection of dementias in early stages. ${ }^{3}$ Good levels of sensitivity have been reported in the distinction between healthy controls and patients with some type of dementia in initial stages. ${ }^{4,7}$

Research reports that ACE-III is one of the most sensitive screening tools for the detection of dementia, compared to other screening tests such as MMSE and MOCA. ${ }^{3}$ It has been reported that a cutoff point of 61 on the ACE-III is sensitive for distinguishing mild dementia from moderate dementia. ${ }^{16}$ Considering that the ACE-III has properties similar to that of its predecessors, it can be considered to be a useful instrument for longitudinal follow-ups as its predecessors. ${ }^{29,30}$

In addition, the value of ACE-III for discriminating between Alzheimer's dementia and fronto-temporal dementia has been reported. ${ }^{4,7,28,31}$ Patients with Alzheimer dementia and fronto-temporal dementia showed significant differences in the performance on the different components of the ACE: orientation, attention, and memory were worse in Alzheimer patients, while the fluency with letters, language, and names were worse in patients with fronto-temporal dementia. Mathuranath, using the ACE and the ACE-R, ${ }^{1,3}$ translated this scoring pattern into an index that is considered useful for the differentiation of both types of dementia (the VLOM ratio). Many different researchers have shown the usefulness of the new version of the ACE. ${ }^{4,7,28,31}$

On the other hand, the usefulness of the annualized change rates $(\mathrm{ARC})$ in the total $\mathrm{ACE}$ scores was reported. This can be calculated using the total score in the previous and current $\mathrm{ACE}$ and the number of months between both evaluations, according to this formula: ARC of ACE $=$ [(last ACE scorebaseline $\mathrm{ACE}$ score $) /($ months between evaluation $)] \times 12 .{ }^{29,30}$

\section{Stroke}

Stroke can involve physical and cognitive impairments. To the best of our knowledge, there is only one study that studied the utility of the ACE-III in the detection of cognitive impairment after stroke. ${ }^{19}$ As an advantage, the ACE-III not only provides the clinician with a cutoff point but also shows an estimated cognitive profile of the patient. ${ }^{7}$ In this way, it provides the clinician with useful information about the cognitive functions of the patient. Moreover, the application of a screening tool can accelerate the diagnostic process of cognitive deficit after stroke and implementing cognitive rehabilitation. ${ }^{32}$ 
It is fundamental when interpreting the cutoff points after stroke to understand that because many of the subtests of the ACE-III cannot be evaluated. In this way, the vast majority of patients after stroke score below the cutoff point. ${ }^{19}$ This is due to the fact that many patients after the stroke typically present with motor difficulties, which negatively impacts the motor output subtests (example: drawing) and often have difficulties in the with language, many times because they present with aphasia. ${ }^{33}$

\section{Parkinson}

Currently, there are no studies that have studied the accuracy of ACE-III in the seeking of cognitive impairment in Parkinson disease (PD). Nevertheless, the coping of the wire cube, present in the visuospatial domain of ACE-III, has correlated significantly with a poor performance on other cognitive domains, suggesting that is a sensitive detector of cognitive impairment in PD. ${ }^{34}$

\section{Variables to consider in the interpretation of the cutoff points}

Previous studies with the ACE-R have shown that the cutoff points are influenced by sociodemographic variables..$^{35,36}$ In several studies, with the ACE-III in several studies, the influence of demographic variables has been considered as seen to be an important variable to take into account when interpreting the suggested cutoff points and to improve diagnostic accuracy. $9,38,40,44,46$

\section{Years of education}

The years of education are an important variable that must be taken into account in order to correctly interpret the cutoff points of the ACE III. Level of education has been observed to have an effect on the accuracy of this screening test in the diagnosis of dementia ${ }^{15,37-40}$ and may be attributable to the presence of items dependent on the level of education or literacy, ${ }^{40}$ such as the use of irregular words, phonemic verbal fluency, ${ }^{41}$ naming task, ${ }^{42}$ and constructional abilities. ${ }^{43}$ Previous investigations have shown that the level of education has a significant impact on both the total score and the scores of the domains. ${ }^{44,45}$ Thus, different cut points have been proposed depending on years of education ${ }^{44}$ and correction factors have been proposed to adjust the raw scores and equivalent scores with cutoff values. ${ }^{46}$

\section{Age}

It has been found that people over 75 years old score less on the ACE-R in comparison with younger people. ${ }^{47,48}$ Interpretation of the cognitive profile is thus limited by age, suggesting that age is an independent predictor of performance. ${ }^{9,15,40}$ It has been shown that all sub-scores of the ACE-III were influenced by age, being orientation, repetition of three words, and serial subtraction of the less affected by this variable. ${ }^{38}$ Hence, it is essential to ensure appropriate cutoff point for older age groups, because the prevalence of cognitive impairment increases with age..$^{9,38}$

\section{IQ}

It has been suggested that the cutoff points for screening techniques should be adjusted depending on the premorbid IQ of the patient, for better sensitivity in the detection of dementia. ${ }^{49}$ In previous studies, the cutoff scores of the $\mathrm{MMSE}^{50}$ and $\mathrm{MOCA}^{49}$ have been associated with premorbid IQ. Likewise, the ACE-III cutoff points were also affected by variation in premorbid IQ. ${ }^{40}$ Therefore, the cutoff points must be adjusted to the premorbid IQ values to ensure correct interpretation.

\section{Translation of different languages}

Mirza et al (2017) performed a review of all the reports of translation and cultural adaptation procedures of the cognitive examination of Addenbrooke version III (ACE-III) and its predecessors. ${ }^{51}$ In this review, it was reported that the first version of ACE is available in 12 languages, the revised version in 16 languages and the third version in 4 languages. Stott et al (2017) reported that only two studies evaluated the ACE-III, but in these studies the ACE-III showed very similar results to those of the ACE-R and these results could be applied equally to the ACE-R. ${ }^{40}$

In Table 2, the different versions of ACE-III currently available are listed.

\section{ACE mobile}

ACE mobile was designed by Newman et al (2018) to support users of the ACE-III by guiding and automating the administration, rule adherence, scoring, and reporting. The new version of the ACE-III, ACE mobile, is an iPad version. The aim is to support the clinician in capturing accurate measurement with zero measurement error. ACE mobile is very effective at reducing errors when compared with the standard paperand-pen test. ACE mobile is currently provided as a free tool, with no restrictions for clinical use, available on iTunes. ${ }^{52}$

\section{M-ACE}

The Mini-Addenbrooke's Cognitive Examination (M-ACE) is a short version of the ACE and was developed and validated in dementia patients. ${ }^{3,53}$ The M-ACE consists of 5 items with 
Table 2 Different versions of ACE-III currently available

\begin{tabular}{|c|c|c|c|c|c|c|}
\hline Languages & Authors & Year & Patient & $\begin{array}{l}\text { Cutoff } \\
\text { score }\end{array}$ & Sensitivity & Specificity \\
\hline English & Jubb and Evans ${ }^{37}$ & 2015 & $\begin{array}{l}\text { Dementia }(n=33) \\
\text { No dementia }(n=26)\end{array}$ & 81 & 79 & 96 \\
\hline English & Hsieh et $\mathrm{al}^{4}$ & 2013 & $\begin{array}{l}\text { Fronto-temporal dementia }(n=33) \\
\text { Alzheimer's disease }(n=28) \\
\text { Healthy controls }(n=25)\end{array}$ & 88 & 100 & 96 \\
\hline English & Elamin et $\mathrm{al}^{28}$ & 2016 & $\begin{array}{l}\text { Subjective memory impairment }(n=15) \\
\text { Alzheimer's disease }(n=3 I) \\
\text { Primary progressive aphasia }(n=I I) \\
\text { Behavioural-variant fronto-temporal } \\
\text { dementia }(n=18) \\
\text { Posterior cortical atrophy }(n=I I) \\
\text { Healthy controls }(n=28)\end{array}$ & 88 & 91.5 & 96.4 \\
\hline Portuguese & Peixoto et $\mathrm{al}^{54}$ & 2018 & $\begin{array}{l}\text { Healthy controls }(n=30) \\
\mathrm{MCl}(n=30) \\
\text { Dementia }(n=30)\end{array}$ & 82 & 87.5 & 57.14 \\
\hline Spanish (European) & Matias-Guiu et $\mathrm{a}^{44}$ & 2015 & $\begin{array}{l}\text { Dementia }(n=87) \\
\text { Healthy controls }(n=\mid 30)\end{array}$ & 65.6 & 83 & 80 \\
\hline Spanish (European) & Matias-Guiu et $\mathrm{al}^{7}$ & 2017 & $\begin{array}{l}\text { Healthy controls }(n=25) \\
\text { Subjective memory complaints }(n=48) \\
\text { Amnestic } M C l(n=47) \\
\text { Mild Alzheimer's disease }(n=47) \\
\text { Other neurodegenerative diseases }(n=33)\end{array}$ & $73 / 74$ & 76.6 & 75 \\
\hline Spanish (European) & Matías-Guiu et al ${ }^{38}$ & 2016 & Healthy controls $(n=273)$ & $7 / 8^{a}$ & 83.1 & 92.4 \\
\hline Spanish (Argentinian) & Bruno et $\mathrm{al}^{31}$ & 2018 & $\begin{array}{l}\text { Fronto-temporal dementia }(n=3 \mid) \\
\text { Alzheimer's disease, }(n=70) \\
\text { Healthy controls }(N=139)\end{array}$ & 86 & 98.5 & 82.01 \\
\hline Egyptian Arabic & Qassem et al ${ }^{55}$ & 2015 & Healthy controls $(\mathrm{N}=139)$ & b & & \\
\hline Italian & Pigliautile et $\mathrm{al}^{46}$ & 2018 & Healthy controls $(\mathrm{N}=574)$ & c & & \\
\hline Thai & Charernboon et a ${ }^{56}$ & 2016 & $\begin{array}{l}\text { Dementia }(n=30) \\
\mathrm{MCl}(n=29) \\
\text { Healthy controls }(n=48)\end{array}$ & 61 & 100 & 97 \\
\hline Chinese & Wang et al ${ }^{15}$ & 2017 & $\begin{array}{l}\text { Dementia }(\mathrm{N}=\mid 77) \\
\text { Healthy controls }(\mathrm{N}=\mid 80)\end{array}$ & 83 & 91.1 & 83.1 \\
\hline
\end{tabular}

Notes: ${ }^{a}$ The author proposes a correction by age, gender, and level of education. ${ }^{\mathrm{T}}$ The author proposes percentiles by the total score and subtest, and no cutoff. ${ }^{\mathrm{C} T h e}$ author proposes a correction by age, gender, and level of education use the cutoff original.

Abbreviations: ACE-III, Addenbrooke's cognitive examination III; MCl, mild cognitive impairment.

a maximum score of 30 . Hsieh et al (2014) identified two cutoffs: 1 ) $\leq 25 / 30$ has both high sensitivity and specificity and 2$) \leq 21 / 30$ is almost certainly a score to have come from a dementia patient regardless of the clinical setting. It has been found to be superior to the MMSE and MoCA in diagnostic utility. Although relatively good levels of sensitivity have been reported, the use of this tool should be questioned in clinical trials where high specificity and low false positive rates are more desirable. ${ }^{18,24}$

\section{Conclusion}

The ACE-III is a screening technique that is capable of differentiating patients with and without cognitive impairment and is sensitive to the early stages of dementia.
Unlike other screening tests (MMSE, MOCA, RUDAS), the ACE-III provides the clinician with a brief multicomponent cognitive profile, since it provides specific scores for different cognitive domains: attention, memory, verbal fluency, language, and visuospatial function. It has been demonstrated that the subtests of the ACE-III have significant correlations with neuropsychological test specific for that domain.

Currently, in addition to the English version there are versions in Spanish, Italian, Chinese, Portuguese, Egyptian Arabic, and Thai.

ACE-III is influenced by demographic variables including age, education, and IQ. All of these are considered to be important variables to take into account when 
interpreting the suggested cutoff points in order to improve diagnostic accuracy.

Future investigations should investigate the utility of the ACE-III in other neurological and psychiatric pathologies, such as head trauma and mood disorders.

\section{Disclosure}

The authors report no conflicts of interest in this work.

\section{References}

1. Mathuranath PS, Nestor PJ, Berrios GE, Rakowicz W, Hodges JR. A brief cognitive test battery to differentiate Alzheimer's disease and frontotemporal dementia. Neurology. 2000;55(11):1613-1620.

2. Folstein MF, Folstein SE, McHugh PR, Se F. "Mini-mental state". A practical method for grading the cognitive state of patients for the clinician. J Psychiatr Res. 1975;12(3):189-198.

3. Hodges JR, Larner AJ. Addenbrooke's Cognitive Examinations: ACE, ACE-R, ACE-III, ACEapp, and M-ACE. In: Cognitive Screening Instruments: A Practical Approach, Second Edition. Springer, Berlin, Alemania. 2017:109-137.

4. Hsieh S, Schubert S, Hoon C, Mioshi E, Hodges JR. Validation of the Addenbrooke's cognitive examination III in frontotemporal dementia and Alzheimer's disease. Dement Geriatr Cogn Disord. 2013; 36(3-4):242-250.

5. Seshadri M, Mazi-Kotwal N. A copyright-free alternative to the minimental state examination is needed. BMJ. 2013;346(7889):8589.

6. Ballard CK, Alistar BNE, Corbett AK, Livingston GU, Rasmussen JR. Helping you to assess cognition: a practical toolkit for clinicians. Alzheimer's Soc Dep Heal. 2015:1-42.

7. Matias-Guiu JA, Cortés-Martínez A, Valles-Salgado M, et al. Addenbrooke's cognitive examination III: diagnostic utility for mild cognitive impairment and dementia and correlation with standardized neuropsychological tests. Int Psychogeriatr. 2017;29(1):105-113.

8. So M, Foxe D, Kumfor F, et al. Addenbrooke's cognitive examination III: psychometric characteristics and relations to functional ability in dementia. J Int Neuropsychol Soc. 2018;24(8):854-863.

9. Cheung G, Clugston A, Croucher M, et al. Performance of three cognitive screening tools in a sample of older new Zealanders. Int Psychogeriatr. 2015;27(6):981-989.

10. Nasreddine ZS, Phillips NA, Bédirian V, et al. The Montreal Cognitive Assessment, MoCA: a brief screening tool for mild cognitive impairment. J Am Geriatr Soc. 2005;53(4):695-699.

11. Rowland JT, Basic D, Storey JE, Conforti DA. The Rowland Universal Dementia Assessment Scale (RUDAS) and the Folstein MMSE in a multicultural cohort of elderly persons. Int Psychogeriatr. 2006;18(1):111-120.

12. Matías-Guiu JA, Fernández-Bobadilla R, Cortés-Martínez A. Addenbrooke's cognitive examination III: un test neuropsicológico útil para el cribado Y La obtención de perfiles cognitivos. Neurología. 2018;33(2): 140 .

13. Burrell JR, Piguet O. Lifting the veil: how to use clinical neuropsychology to assess dementia. J Neurol Neurosurg Psychiatry. 2015; 86(11):1216-1224.

14. Slachevsky A, Villalpando JM, Sarazin M, Hahn-Barma V, Pillon B, Dubois B. Frontal assessment battery and differential diagnosis of frontotemporal dementia and Alzheimer disease. Arch Neurol. 2004;61(7): 1104-1107.

15. Wang BR, Ou Z, Gu XH, Wei CS, Xu J, Shi JQ. Validation of the Chinese version of Addenbrooke's cognitive examination III for diagnosing dementia. Int J Geriatr Psychiatry. 2017;32(12):e173-e179.

16. Giebel CM, Challis D. Sensitivity of the mini-mental state examination, Montreal cognitive assessment and the Addenbrooke's cognitive examination III to everyday activity impairments in dementia: an exploratory study. Int J Geriatr Psychiatry. 2017;32(10):1085-1093.
17. Matías-Guiu JA, Valles-Salgado M, Rognoni T, Hamre-Gil F, MorenoRamos T, Matías-Guiu J. Comparative diagnostic accuracy of the ACE-III, MIS, MMSE, MoCA, and RUDAS for screening of Alzheimer disease. Dement Geriatr Cogn Disord. 2017;43(5-6):237-246.

18. Larner AJ. Speed versus accuracy in cognitive assessment when using CSIs. Prog Neurol Psychiatry. 2015;19(1):21-24.

19. Lees RA, Hendry Ba K, Broomfield N, Stott D, Larner AJ, Quinn TJ. Cognitive assessment in stroke: feasibility and test properties using differing approaches to scoring of incomplete items. Int J Geriatr Psychiatry. 2017;32(10):1072-1078.

20. Parra MA, Baez S, Allegri R, et al. Dementia in Latin America: assessing the present and envisioning the future. Neurology. 2018;90(5):222-231.

21. Dharmarajan TS, Gunturu SG. Alzheimer's disease: a healthcare burden of epidemic proportion. Am Heal Drug Benefits. 2009;2(1):39-47.

22. Shah H, Albanese E, Duggan C, et al. Research priorities to reduce the global burden of dementia by 2025. Lancet Neurol. 2016;15(12): 1285-1294.

23. Panegyres PK, Berry R, Burchell J. Early dementia screening. Diagnostics. 2016;6(1):1-13.

24. Larner AJ. Cognitive screening instruments for the diagnosis of mild cognitive impairment. Prog Neurol Psychiatry. 2016;20(2):21-26.

25. Litvan I, Goldman JG, Tröster AI, et al. Diagnostic criteria for mild cognitive impairment in Parkinson's disease: movement disorder society Task Force guidelines. Mov Disord. 2012;27(3):349-356.

26. Gorelick PB, Scuteri A, Black SE, et al; American Heart Association Stroke Council. Vascular contributions to cognitive impairment and dementia: a statement for healthcare professionals from the American Heart Association/American Stroke Association. Stroke. 2011;42(9):2672-2713.

27. de Mendonça A, Ribeiro F, Guerreiro M, Garcia C. Frontotemporal mild cognitive impairment. J Alzheimers Dis. 2004;6(1):1-9.

28. Elamin M, Holloway G, Bak TH, Pal S. The utility of the Addenbrooke's cognitive examination version three in early-onset dementia. Dement Geriatr Cogn Disord. 2016;41(1-2):9-15.

29. Leyton CE, Hornberger M, Mioshi E, Hodges JR. Application of Addenbrooke's cognitive examination to diagnosis and monitoring of progressive primary aphasia. Dement Geriatr Cogn Disord. 2010;29(6): 504-509.

30. Rascovsky K, Salmon DP, Hansen LA, Galasko D. Distinct cognitive profiles and rates of decline on the Mattis Dementia Rating Scale in autopsy-confirmed frontotemporal dementia and Alzheimer's disease. J Int Neuropsychol Soc. 2008;14(3):373-383.

31. Bruno D, Slachevsky A, Fiorentinoa N, et al. Validación argentinochilena de la versión en espanol del test Addenbrooke's Cognitive Examination III para el diagnóstico de demencia. Neurologia. 2018; S0213-4853(17):30250-30255.

32. Fiedorova D, Krulova P, Ressner P, et al. Addenbrooke's cognitive examination in nondemented patients after stroke. Neuropsychiatry. 2018;8(2):505-512.

33. Engelter ST, Gostynski M, Papa S, et al. Epidemiology of aphasia attributable to first ischemic stroke: incidence, severity, fluency, etiology, and thrombolysis. Stroke. 2006;37(6):1379-1384.

34. Alty JE, Cosgrove J, Jamieson S, Smith SL, Possin KL. Which figure copy test is more sensitive for cognitive impairment in Parkinson's disease: wire cube or interlocking pentagons? Clin Neurol Neurosurg. 2015;139:244-246.

35. Nieto A, Galtier I, Hernández E, Velasco P, Barroso J. Addenbrooke's cognitive examination-revised: effects of education and age. Normative data for the Spanish speaking population. Arch Clin Neuropsychol. 2016;31(7):811-818.

36. Pigliautile M, Chiesi F, Rossetti S, et al. Normative data for the ACE-R in an Italian population sample. Neurol Sci. 2015;36(12):2185-2190.

37. Jubb MT, Evans JJ. An investigation of the utility of the Addenbrooke's cognitive examination III in the early detection of dementia in memory clinic patients aged over 75 years. Dement Geriatr Cogn Disord. 2015; 40(3-4):222-232. 
38. Matías-Guiu JA, Fernández-Bobadilla R, Fernández-Oliveira A, et al. Normative data for the Spanish version of the Addenbrooke's cognitive examination III. Dement Geriatr Cogn Disord. 2016;41(5-6):243-250.

39. Sousa L, Vivas L. Valores normativos del Addenbrooke's Cognitive Examination (ACE) para población Con bajo nivel socioeducativo. Neurología Argentina. 2017;9(4):219-224.

40. Stott J, Scior K, Mandy W, Charlesworth G, Brandt J. Dementia screening accuracy is robust to premorbid IQ variation: evidence from the Addenbrooke's cognitive examination-III and the test of premorbid function. J Alzheimers Dis. 2017;57(4):1293-1302.

41. da Silva CG, Petersson KM, Faísca L, Ingvar M, Reis A. The effects of literacy and education on the quantitative and qualitative aspects of semantic verbal fluency. J Clin Exp Neuropsychol. 2004;26(2):266-277.

42. Reis A, Petersson KM, Castro-Caldas A, Ingvar M. Formal schooling influences two- but not three-dimensional naming skills. Brain Cogn. 2001;47(3):397-411.

43. Ostrosky-Solis F, Ardila A, Rosselli M, Lopez-Arango G, UrielMendoza V. Neuropsychological test performance in illiterate subjects. Arch Clin Neuropsychol. 1998;13(7):645-660.

44. Matias-Guiu JA, Fernández de Bobadilla R, Escuderoa G, et al. Validation of the Spanish version of Addenbrooke's cognitive examination III for diagnosing dementia. Neurologia. 2015;30:545-551. English, Spanish.

45. García-Caballero A, García-Lado I, González-Hermida J, et al. Validation of the Spanish version of the Addenbrooke's cognitive examination in a rural community in Spain. Int J Geriatr Psychiatry. 2006;21(3):239-245.

46. Pigliautile M, Chiesi F, Stablum F, et al. Italian version and normative data of Addenbrooke's cognitive examination III. Int Psychogeriatr. 2018;5:1-9.

47. Pigliautile M, Ricci M, Mioshi E, et al. Validation study of the Italian Addenbrooke's cognitive examination revised in a young-old and oldold population. Dement Geriatr Cogn Disord. 2011;32(5):301-307.
48. Callow LM. Assessing cognitive functioning in older adults and its relationship to quality of life; 2013. Available from: https://mro.massey.ac.nz/bitstream/handle/10179/5117/02_whole. pdf? sequence $=2 \&$ is Allowed $=y$

49. Alves L, Simões MR, Martins C, Freitas S, Santana I. Premorbid IQ influence on screening tests' scores in healthy patients and patients with cognitive impairment. J Geriatr Psychiatry Neurol. 2013;26(2): 117-126.

50. Starr JM, Lonie J. The influence of pre-morbid IQ on Mini-Mental State examination score at time of dementia presentation. Int J Geriatr Psychiatry. 2007;22(4):382-384.

51. Mirza N, Panagioti M, Waheed MW, Waheed W. Reporting of the translation and cultural adaptation procedures of the Addenbrooke's Cognitive Examination version III (ACE-III) and its predecessors: a systematic review. BMC Med Res Methodol. 2017;17(1):1-10.

52. Newman CGJ, Bevins AD, Zajicek JP, et al. Improving the quality of cognitive screening assessments: ACEmobile, an iPad-based version of the Addenbrooke's cognitive Examination-III. Alzheimers Dement. 2018;10:182-187.

53. Hsieh S, McGrory S, Leslie F, et al. The mini-Addenbrooke's cognitive examination: a new assessment tool for dementia. Dement Geriatr Cogn Disord. 2015;39(1-2):1-11.

54. Peixoto B, Machado M, Rocha P, et al. Validation of the Portuguese version of Addenbrooke's cognitive examination III in mild cognitive impairment and dementia. Adv Clin Exp Med. 2018;27(6):781-786.

55. Qassem T, Khater MS, Emara T, et al. Normative data for healthy adult performance on the Egyptian-Arabic Addenbrooke's Cognitive Examination III. Middle East Curr Psychiatr. 2015;22(1):27-36.

56. Charernboon T, Jaisin K, Lerthattasilp T. The Thai version of the Addenbrooke's cognitive examination III. Psychiatry Investig. 2016; 13(5):571-573.
Neuropsychiatric Disease and Treatment

\section{Publish your work in this journal}

Neuropsychiatric Disease and Treatment is an international, peerreviewed journal of clinical therapeutics and pharmacology focusing on concise rapid reporting of clinical or pre-clinical studies on a range of neuropsychiatric and neurological disorders. This journal is indexed on PubMed Central, the 'PsycINFO' database and CAS,

\section{Dovepress}

and is the official journal of The International Neuropsychiatric Association (INA). The manuscript management system is completely online and includes a very quick and fair peer-review system, which is all easy to use. Visit http://www.dovepress.com/testimonials.php to read real quotes from published authors. 